\title{
Common humpback whale (Megaptera novaeangliae) sound types for passive acoustic monitoring
}

\author{
Alison K. Stimpert ${ }^{\text {a) }}$ and Whitlow W. L. Au \\ Marine Mammal Research Program, Hawai' i Institute of Marine Biology, P.O. Box 1106, Kailua, \\ Hawaii 96734 \\ Susan E. Parks \\ Applied Research Laboratory, The Pennsylvania State University, P.O. Box 30, State College, \\ Pennsylvania 16804 \\ Thomas Hurst \\ Advanced Engineering Labs, Woods Hole Oceanographic Institution, Smith 205, 86 Water Street, Woods \\ Hole, Massachusetts 02543 \\ David N. Wiley \\ Stellwagen Bank National Marine Sanctuary, National Oceanic and Atmospheric Administration, 175 Edward \\ Foster Road, Scituate, Massachusetts 02066
}

(Received 27 April 2010; revised 27 August 2010; accepted 27 September 2010)

\begin{abstract}
Humpback whales (Megaptera novaeangliae) are one of several baleen whale species in the Northwest Atlantic that coexist with vessel traffic and anthropogenic noise. Passive acoustic monitoring strategies can be used in conservation management, but the first step toward understanding the acoustic behavior of a species is a good description of its acoustic repertoire. Digital acoustic tags (DTAGs) were placed on humpback whales in the Stellwagen Bank National Marine Sanctuary to record and describe the non-song sounds being produced in conjunction with foraging activities. Peak frequencies of sounds were generally less than $1 \mathrm{kHz}$, but ranged as high as $6 \mathrm{kHz}$, and sounds were generally less than $1 \mathrm{~s}$ in duration. Cluster analysis distilled the dataset into eight groups of sounds with similar acoustic properties. The two most stereotyped and distinctive types ("wops" and "grunts") were also identified aurally as candidates for use in passive acoustic monitoring. This identification of two of the most common sound types will be useful for moving forward conservation efforts on this Northwest Atlantic feeding ground. (C) 2011 Acoustical Society of America.
\end{abstract}

[DOI: 10.1121/1.3504708]

PACS number(s): 43.80.Ka, 43.80.Nd [JAS]

Pages: 476-482

\section{INTRODUCTION}

In recent years, passive acoustics has become a popular method for study of marine mammal behavior and distributions, especially cetaceans (Mellinger et al., 2007; Van Parijs et al., 2009). Passive acoustic monitors and automatic detection algorithms can be used for presence/absence studies if the sounds produced by target species are stereotyped and well described. This can lead to important conservation and management strategies, such as remotely monitoring movements of the highly endangered North Atlantic right whale in order to prevent ship strikes. For example, in a system implemented in the Stellwagen Bank National Marine Sanctuary (SBNMS), off Cape Cod, MA, "smart" buoys record and detect vocalizing right whales, and transmit near realtime whale detection information to alert ships traveling through the sanctuary (Lippsett, 2009; Spaulding et al., 2010). However, many unknown sounds are recorded on a regular basis (e.g., Stafford et al., 1999), and in some cases it can take years to determine what species is actually

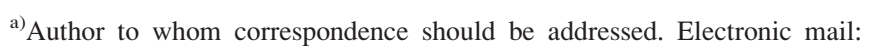
stimpert@hawaii.edu producing the sound, as with the minke whale "boing" sound (Rankin and Barlow, 2005). "Without an understanding of a species' acoustic repertoire... no clear or coherent research or management question can be addressed" (Van Parijs et al., 2009, p. 23).

Humpback whales are one of the best-studied large baleen whales and have one of the most diverse acoustic repertoires. Most famous is their song, which is primarily produced in the lower-latitude breeding waters. Since humpback whale song was first described (Payne and McVay, 1971), a large body of work has been developed to investigate its behavioral context (e.g., Winn et al., 1981; Tyack, 1983; Chu and Harcourt, 1986; Chu, 1988; Frankel et al., 1995; Au et al., 2000; Frazer and Mercado, 2000; Miller et al., 2000; Noad et al., 2000; Au et al., 2001; Au et al., 2006; Darling et al., 2006; Smith et al., 2008). However, a clear understanding of the function of the acoustic display remains elusive. Even less described are "social sounds," or any non-song phonations. A social sound, as defined by Silber, is "any phonation that does not possess the rhythmic and continuous patterning of song" (Silber, 1986, p. 2076). Social sounds are produced during all phases of the yearly life cycle of humpback whales. 
Historic work on social sounds was completed on the Alaskan feeding grounds. Thompson et al. (1986) described five types of aurally classified sounds (moans, grunts, pulse trains, blowhole-associated sounds, and surface impacts). D'Vincent et al. (1985) and Cerchio and Dahlheim (2001) described a distinctive feeding call used in coordinated foraging in Southeast Alaska. No comprehensive description of non-song sounds on the Northwest Atlantic foraging grounds has been published.

Silber (1986) recorded social sounds from humpback whales in Hawai'i, and described behavioral context of sound production, but only reported general acoustic characteristics of the sounds (simple in structure: Mostly frequencymodulated upsweeps under $2 \mathrm{kHz}$ ). Zoidis et al. (2008) also recently documented production of non-song vocalizations from a calf in the Hawaiian breeding grounds waters.

In 2007, Dunlop et al. published the first description of social sounds produced by migrating humpback whales off the eastern coast of Australia. Using 13 acoustic parameters and aural classification as well as several statistical techniques, Dunlop et al. reported 34 discrete call types as produced by the whales, including many that were also heard as part of the song in that area.

The next important step is identification of the most stereotyped, distinctive, and common call types used, which may be location-specific, for the purposes of automatic detection and conservation management, as with the North Atlantic right whales. In fact, some overlap exists between humpback and right whale call types, to the point that the breadth of the humpback repertoire could become a confounding factor for automatic monitoring of other species (Van Parijs et al., 2009). This may particularly be an issue in areas like the Northwest Atlantic, where there is a high diversity of marine mammal species.

To address the need for specific and distinctive sounds that would indicate the presence of humpbacks, we used high-fidelity recordings from non-invasive, digital acoustic tags (DTAGs) (Johnson and Tyack, 2003). Sounds recorded from whales tagged during feeding activities in the Stellwagen Bank National Marine Sanctuary (SBNMS) were described and categorized with the goal of identifying calls that could most efficiently be used for remote monitoring and conservation management.

\section{MATERIALS AND METHODS}

\section{A. Tagging}

To obtain high quality, close range recordings of humpback whale social sounds, DTAGs (Johnson and Tyack, 2003) were deployed on humpback whales exhibiting foraging behavior on the feeding grounds. The tags sampled 16 bit audio at a userdefined sampling rate of either 64 or $96 \mathrm{kHz}$. Acoustic system sensitivity on the tags was $-171 \mathrm{~dB}$ re $1 \mathrm{~V} / \mu \mathrm{Pa}$ (hydrophone sensitivity $-205 \mathrm{~dB}$ re $1 \mathrm{~V} / \mu \mathrm{Pa}, 20 \mathrm{~dB}$ pre-amp gain, $2 \mathrm{~dB}$ analog-to-digital converter (ADC) converter gain, and $12 \mathrm{~dB}$ of user-controlled gain). The tags also contained a Butterworth high pass filter at $400 \mathrm{~Hz}$ to minimize flow noise.

Tags were deployed from a small research vessel using a $15 \mathrm{~m}$ cantilevered pole. Sounds from the feeding grounds were recorded in the Northwest Atlantic Ocean, in the Stellwagen Bank National Marine Sanctuary during 2006.

\section{B. Analysis \\ 1. Detection}

All occurrences of social sounds were identified manually by experienced listeners. Automatic detection algorithms did not produce as accurate or comprehensive results as human auditors, largely due to the inconsistent nature of the background noise and lack of templates for the sounds being sought. Sounds were therefore logged in MATLAB using XBAT (Extensible BioAcoustic Tool; Mills and Figueroa, 2005), by listening to tag records and also by visually examining the spectrograms of the recordings in short enough segments that acoustic events less than $1 \mathrm{~s}$ in duration would be visible. Cetacean sounds were identified based on the qualities described in Sec. I, and most of these below $10 \mathrm{kHz}$ were judged to be humpback-produced, as few other large whale species were known to be in the immediate vicinity, based on visual observations. Clips of background noise of the same length of each sound were pulled from the acoustic record either directly before or after each sound, in order to compare each sound with current ambient noise levels.

\section{Post-processing}

The DTAG hardware contains a single-pole R-C (resistorcapacitor) high pass filter at $400 \mathrm{~Hz}$ in order to minimize flow noise. To compensate for this, a single-pole "low frequency emphasis filter" was used, combining a high pass filter at $40 \mathrm{~Hz}$ and a low pass filter at $400 \mathrm{~Hz}$ (as in Aguilar-Soto et al., 2006). The result, when applied to the signal and noise clips, was a gain of $20 \mathrm{~dB}$ between 40 and $400 \mathrm{~Hz}$. Above $400 \mathrm{~Hz}$, the two filters cancelled out to leave a net flat response, thus re-amplifying both signal and noise clips only in the lower portion of the spectrum. A root-mean-square (rms) signal to noise ratio (SNR) was then calculated using the corresponding noise clip for each signal. The subset of sound clips that contained SNRs greater than $10 \mathrm{~dB}$ was selected for analysis.

\section{Parameter calculation}

For determining the acoustic parameters, the linear spectrum of the corresponding noise clip was subtracted from the spectrum of the corresponding signal clip to remove energy that was due to the ambient environment. In the case of start and end frequencies of the signal, the first and last $10 \%$ of the resulting signal were used to find the starting and ending frequencies of the signal overall, defined below.

Calculated sound parameters related to both frequency and time are listed in Table I and depicted in Fig. 1. Several of these parameters were also used by Dunlop et al. (2007) to classify social sounds on the migration route. The start and end points of each sound were determined manually through visual designation of sample points from a plot of the sound's waveform. The duration of the sound was then calculated from these sample points. Other parameters were calculated using custom-written algorithms in MATLAB. 
TABLE I. Acoustic parameters calculated from sounds recorded on DTAGs, and description of these parameters.

\begin{tabular}{|c|c|c|}
\hline Measurement & Abbreviation & Description \\
\hline Duration of sound (s) & Dur & Length of sound \\
\hline Peak frequency $(\mathrm{Hz})$ & $\mathrm{pkF}$ & Frequency of the spectral peak \\
\hline $3 \mathrm{~dB}$ bandwidth $(\mathrm{Hz})$ & BW & Frequency band between the lower and upper half power points ( $3 \mathrm{~dB}$ down from pkF) in the frequency spectrum \\
\hline Center frequency $(\mathrm{Hz})$ & F0 & $\begin{array}{l}\text { Energy midpoint of the spectrum (energy above and below this frequency are equal); generally a more } \\
\text { representative measure for bimodal or complex signals than is peak frequency }\end{array}$ \\
\hline rms bandwidth $(\mathrm{Hz})$ & BWrms & Frequency band encompassing the standard deviation of the spectrum about the center frequency \\
\hline Start frequency $(\mathrm{Hz})$ & startF & Peak frequency of the signal during the first $10 \%$ of sound duration \\
\hline End frequency $(\mathrm{Hz})$ & endF & Peak frequency of the signal during the last $10 \%$ of sound duration \\
\hline Maximum frequency $(\mathrm{Hz})$ & $\operatorname{maxF}$ & $\begin{array}{l}\text { The highest frequency in the spectrum at which the signal is } 10 \mathrm{~dB} \text { below its level at peak frequency } \\
\text { (high frequency) }\end{array}$ \\
\hline Frequency trend (ratio) & trendF & Start frequency/end frequency \\
\hline
\end{tabular}

We chose to group the sound types using a cluster analysis based on the calculated acoustic parameters in order to objectify the process. Though many studies use human aural classification (e.g., Parks and Tyack, 2005; Au et al., 2006; Deecke and Janik, 2006; Riesch et al., 2006; Dunlop et al., 2007), it is questionable whether any currently used method will identify the features actually salient to and used by the whales themselves. Thus we attempted to make our classification as repeatable as possible. Hierarchical agglomerative cluster analysis in MINITAB 13.3 and MATLAB 7.1 was used to describe natural groupings in the sound data based on selected acoustic parameters (duration, peak frequency, center frequency, rms bandwidth, and maximum frequency). Variables were normalized and log-transformed to minimize skewness and also the effects of scale differences since variables were in different units. The log transformation was also used to better represent mammalian perception of pitch, which is normally logarithmic with respect to frequency in hertz (though there are no direct measures of mysticete hearing). A dendrogram was generated using Mahalanobis distances and Ward's distance linkage method. A parsimonious cutoff point in similarity between groups on this tree was chosen subjectively based on the distance value and amount of information retained, as seen in the graphical output (Fig. 2), resulting in eight clusters of sounds. Sounds in each group were examined visually and aurally to determine a subjective description for the cluster.

\section{RESULTS}

\section{A. General sound characteristics}

Fifteen tags were deployed on Stellwagen Bank during the 2006 feeding season (resulting in $95.3 \mathrm{~h}$ of recorded data). From this dataset, 1542 sounds were of sufficient quality for analysis. Sound parameters were quite variable, with a mean peak frequency of all sounds of $329 \mathrm{~Hz}$, but with a standard deviation $\pm 632 \mathrm{~Hz}$, and peak frequencies ranging as high as $6 \mathrm{kHz}$. Sounds averaged $0.7( \pm 0.5) \mathrm{s}$ in duration, ranging from 0.02 to $6.3 \mathrm{~s}$.

\section{B. Sound types}

Five parameters of the sounds (log-transformed and normalized duration, peak frequency, center frequency, rms bandwidth, and maximum frequency) were selected for use in cluster analysis to attempt a grouping of different sounds based on objective measurements. Figure 2 depicts how the sounds grouped in relation to one another based on those variables. Table II summarizes all the calculated acoustic parameters by sound type from this cluster analysis and includes
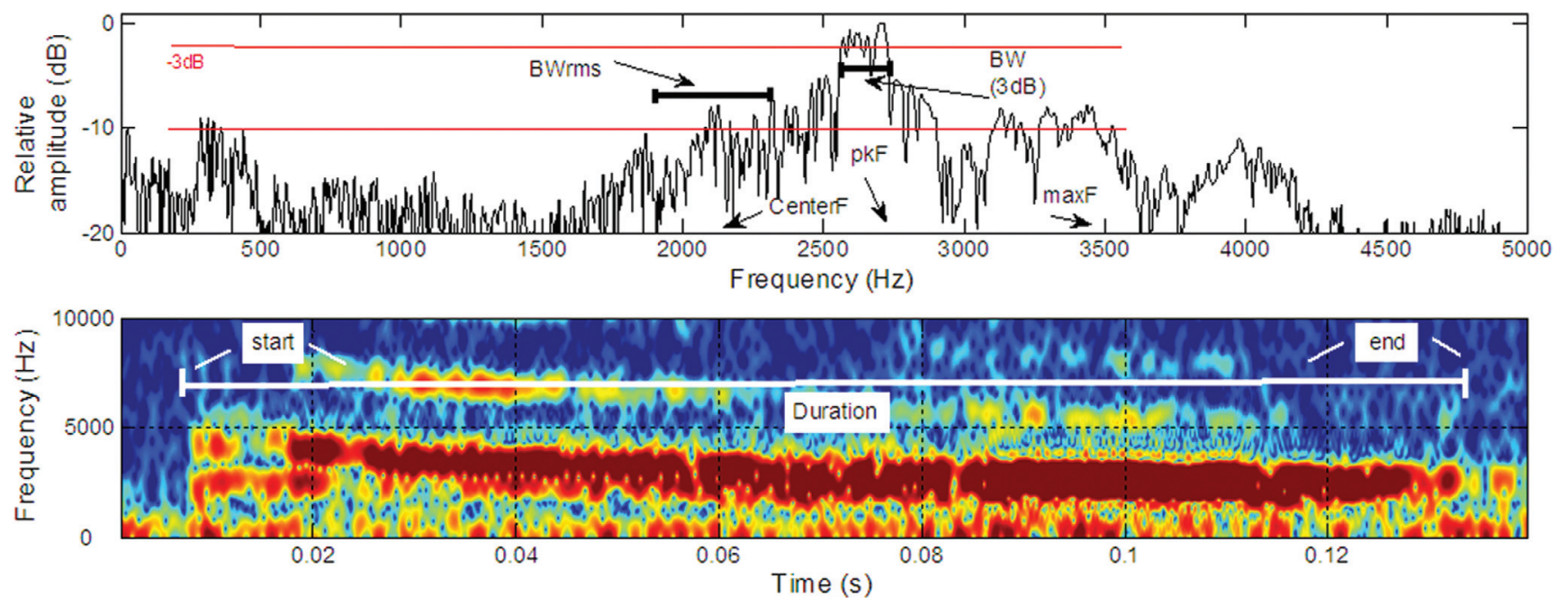

FIG. 1. (Color online) Graphical depiction of the acoustic parameters calculated from sounds recorded on DTAGs. The top panel shows the frequency spectrum of a hypothetical sound, and the bottom panel shows a spectrogram (Hanning window, fast Fourier transform (FFT) size 1024, 99\% overlap). 


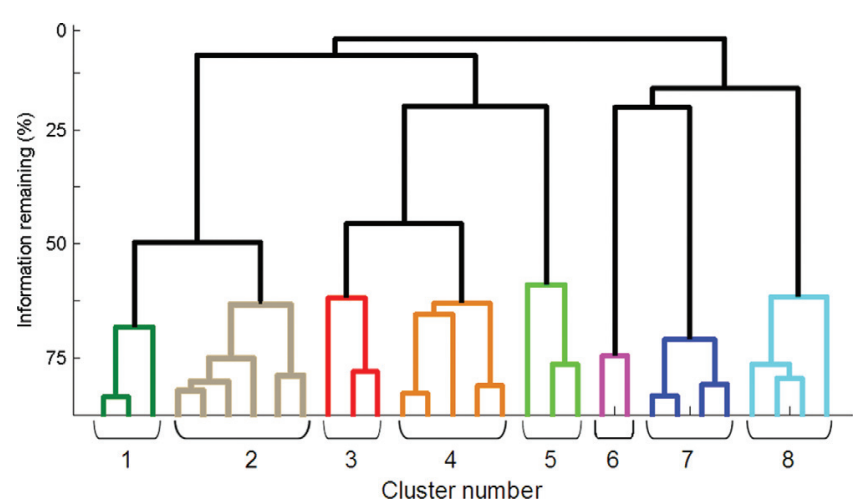

FIG. 2. (Color online) Results of cluster analysis, SBNMS feeding ground, 2006. Each cluster is represented by a different color. Descriptions and acoustic summaries of each cluster are in Table II.

sample sizes in each cluster and subjective descriptions of a sample of sounds in each cluster.

\section{Common sound types for passive acoustic monitoring}

Figure 3 shows examples of two of the most stereotyped and repetitive sound types, which we refer to as "wops" (as in Dunlop et al., 2007, see below) and "grunts." These sounds were pulsive and harmonic upsweeps, respectively. The wops were aurally similar to the wops described in Dunlop et al. (2007) but were longer in duration by approximately $0.5 \mathrm{~s}$. Wops are also similar to units called "pulse trains" in some song recordings (D. Cholewiak, personal communication). Example wave files for both of these sound types are included as supplementary material accompanying this manuscript (multimedia files 1 and 2). ${ }^{1}$ After the cluster analysis, manual identification of all wops and grunt bouts in the dataset was completed, resulting in 523 occurrences of wops, with an average duration of $1.14( \pm 0.27) \mathrm{s}$ (multimedia file 1). Grunts generally occurred in bouts of $4( \pm 1)$ units (565 bouts were identified), at a rate of $1.8( \pm 0.3)$ grunts/s (multimedia file 2).

Table III shows call type by tag record, indicating that multiple individuals produced all the calls. Though there is overlap between the automatically generated clusters, this distribution by tag also gives weight to the judgment that wops and grunts are the most commonly used call types and likely the most appropriate for passive acoustic monitoring.

\section{DISCUSSION}

The humpback whale social sounds described here were low in frequency [under $500 \mathrm{~Hz}$ peak frequency, but ranging as high as $12 \mathrm{kHz}$ for the maximum frequency ("high frequency," see Table I) in a sound] and short in duration [generally less than $1 \mathrm{~s}$, compared to song units, which are frequently $1 \mathrm{~s}$ or more (Au et al., 2006)]. The sounds in this dataset are in many cases higher in frequency than those reported by Dunlop et al. (2007) and shorter in duration. The differences in duration may be related to the behavioral timing of the studies. Dunlop et al.'s recordings were made on the migration route and included many units that were also part of the song, which tend to be longer in duration. The frequency discrepancy may largely be due to differences in methodology. The necessary high pass filter for flow noise in the DTAG hardware, and resulting required post-processing including the filter compensation, is a drawback when making acoustic measurements on low frequency baleen whale sounds. Especially those sounds with large amounts of energy below $100 \mathrm{~Hz}$ may not be accurately represented acoustically. Thus, the same sound recorded on Dunlop et al.'s array and

TABLE II. Summary of acoustic parameters by sound "type" or cluster, SBNMS Feeding grounds, 2006. Mean parameters are in bold. Standard deviations are listed below each variable, and number of observations in each cluster is in parentheses after the cluster number. Description was subjectively determined after listening to a sample of the cluster and viewing plots of the sound waveforms.

\begin{tabular}{|c|c|c|c|c|c|c|c|c|c|c|}
\hline Cluster No. & Description & $\begin{array}{l}\text { Duration } \\
\text { (s) }\end{array}$ & $\begin{array}{l}\mathrm{pkF} \\
(\mathrm{Hz})\end{array}$ & $\begin{array}{l}\text { F0 } \\
(\mathrm{Hz})\end{array}$ & $\begin{array}{c}\text { BWrms } \\
(\mathrm{Hz})\end{array}$ & $\begin{array}{l}\mathrm{BW} \\
(\mathrm{Hz})\end{array}$ & $\begin{array}{c}\text { startF } \\
(\mathrm{Hz})\end{array}$ & $\begin{array}{l}\text { endF } \\
(\mathrm{Hz})\end{array}$ & $\begin{array}{c}\operatorname{maxF} \\
(\mathrm{Hz})\end{array}$ & $\begin{array}{c}\text { trendF } \\
\text { (startF/endF) }\end{array}$ \\
\hline \multirow[t]{2}{*}{$1(N=152)$} & Grunts/upsweeps & 0.24 & 211 & 450 & 404 & 180 & 344 & 265 & 937 & 39.60 \\
\hline & & 0.15 & 138 & 244 & 154 & 291 & 413 & 391 & 567 & 164.46 \\
\hline \multirow{2}{*}{$2(N=276)$} & Short grunts/upsweeps & 0.27 & 376 & 421 & 300 & 177 & 277 & 249 & 584 & 25.15 \\
\hline & & 0.14 & 280 & 241 & 187 & 280 & 392 & 335 & 450 & 130.10 \\
\hline \multirow[t]{2}{*}{$3(N=101)$} & Moans and squeaks & 0.94 & 1039 & 1048 & 372 & 232 & 545 & 708 & 1315 & 15.75 \\
\hline & & 1.03 & 950 & 918 & 241 & 275 & 791 & 954 & 1017 & 119.43 \\
\hline \multirow[t]{2}{*}{$4(N=214)$} & Upsweep gurgle & 0.77 & 803 & 1149 & 973 & 483 & 370 & 380 & 1892 & 20.18 \\
\hline & & 0.58 & 1303 & 1204 & 627 & 1028 & 777 & 596 & 1701 & 148.97 \\
\hline \multirow[t]{2}{*}{$5(N=146)$} & Grunts and wops & 0.64 & 137 & 738 & 670 & 419 & 411 & 342 & 1335 & 23.35 \\
\hline & & 0.51 & 73 & 574 & 478 & 776 & 873 & 541 & 979 & 210.34 \\
\hline \multirow[t]{2}{*}{$6(N=371)$} & Wops & 1.08 & 110 & 176 & 208 & 38 & 144 & 123 & 229 & 1.98 \\
\hline & & 0.30 & 39 & 55 & 75 & 48 & 173 & 121 & 103 & 6.44 \\
\hline \multirow[t]{2}{*}{$7(N=111)$} & Paired bursts and low grumbles & 0.42 & 108 & 207 & 645 & 61 & 137 & 112 & 312 & 40.66 \\
\hline & & 0.19 & 55 & 203 & 399 & 73 & 190 & 237 & 511 & 151.91 \\
\hline \multirow[t]{2}{*}{$8(N=171)$} & Wops and upsweep grunts & 0.74 & 125 & 369 & 533 & 23 & 311 & 246 & 193 & 4.31 \\
\hline & & 0.43 & 77 & 219 & 428 & 32 & 428 & 489 & 102 & 14.40 \\
\hline
\end{tabular}



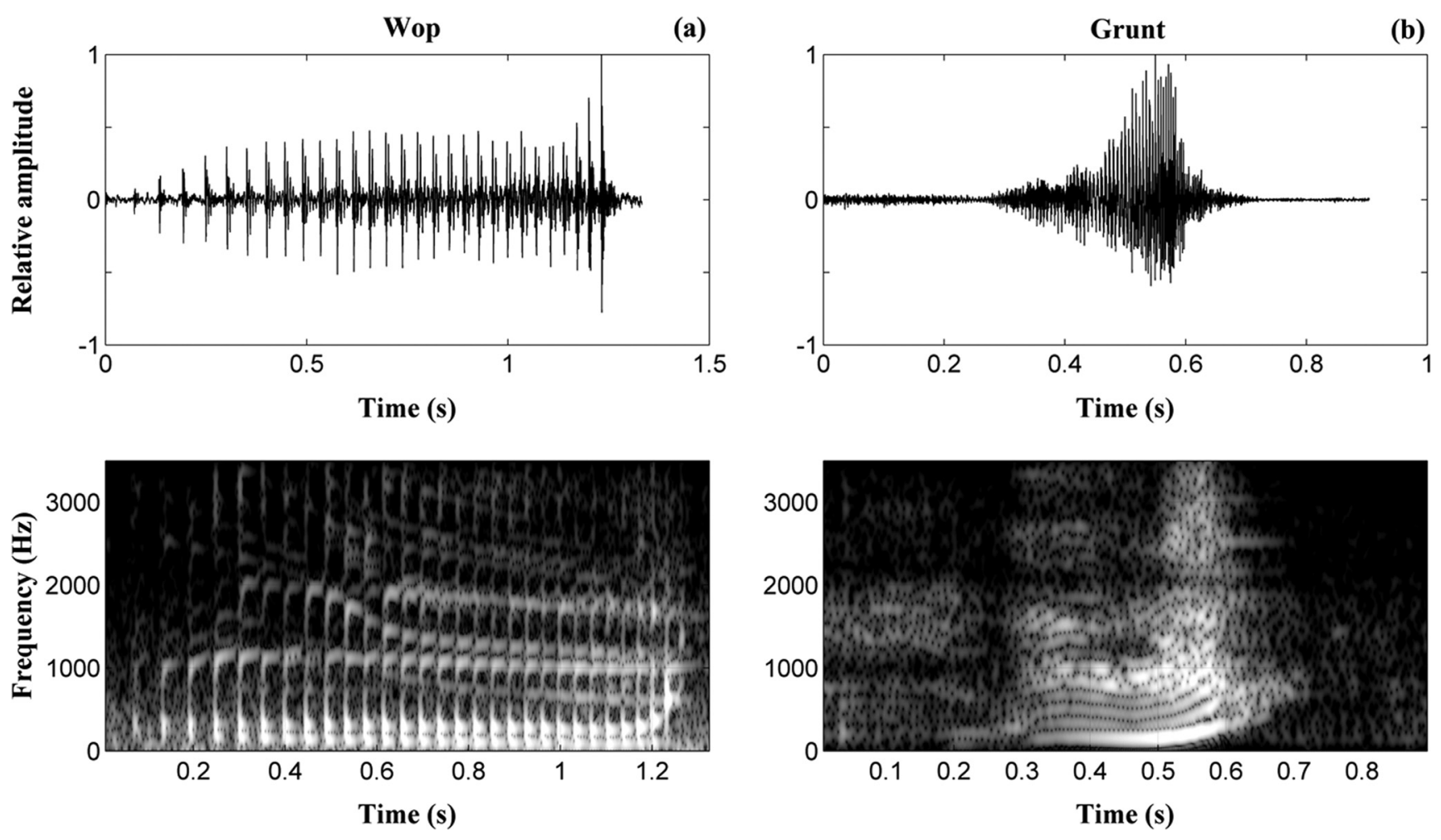

FIG. 3. Example waveforms and spectrograms for the two most common and distinctive sound types identified via cluster analysis and confirmed aurally (Hanning window, FFT size 2048, 99\% overlap). Wops (a) were produced singularly, and grunts generally occurred in bouts containing several similar grunts [panel (b) shows one of these units]. Note the difference in time scales.

the DTAGs in this study may appear higher in frequency in this dataset. However, tags are an excellent way to record sounds at a consistently close range and allow comparison of sound production with behavior. This method also allows many quieter sounds to be captured, and sounds to be recorded without the attenuation and distortion that may occur over long distances. Some of the higher frequency information might be retained in this dataset's recordings for that reason as well.

The cluster analysis was successful in distilling the dataset into a small number of groups of similar sound types. Though membership in these groups has some overlap according to the human ear, related groups as seen in the dendrogram (Fig. 2) do have some similar sound types, giv- ing weight to the classification. The analysis also broke out two main sound types that were confirmed distinctive from an aural perspective and from visual inspection of the waveform (Fig. 3): The wop (cluster 6, and partially clusters 5 and 8) and the grunt (cluster 2, and partially clusters 1 and 5). Dunlop et al. (2007) termed two of their most commonly recorded sounds the wop and the thwop. These two sounds were both brief harmonic upsweeps, and together comprised approximately $20 \%$ of the 660 sounds recorded. Our dataset also contained a large number of sounds aurally similar to these, if slightly longer in duration, hence our choice to also call these sounds wops.

We also recorded several wops on the breeding grounds, even given the small sample size (unpublished data). That

TABLE III. Proportion of each animal's record's sounds that were of sufficient quality for analysis and then also a certain type/cluster number. Values in bold represent sound types that comprised more than $5 \%$ of the sound production for a given whale's acoustic record. "Total" is the total number of sounds recorded of that type/cluster number (column) or on that animal's record (row). The two largest clusters (2 and 6) represent the two sound types highlighted in this paper as common and distinctive humpback sounds.

\begin{tabular}{|c|c|c|c|c|c|c|c|c|c|c|c|c|c|c|c|c|c|}
\hline \multirow{2}{*}{$\begin{array}{l}\text { Cluster } \\
\text { No. }\end{array}$} & & \multicolumn{15}{|c|}{ Tag No. } & \multirow{2}{*}{$\begin{array}{c}\text { Total } \\
\text { number } \\
\text { of sounds }\end{array}$} \\
\hline & & $188 \mathrm{a}$ & $188 \mathrm{~b}$ & $189 \mathrm{a}$ & $189 \mathrm{~b}$ & $189 \mathrm{c}$ & $192 \mathrm{a}$ & $192 b$ & $195 \mathrm{a}$ & $195 b$ & $196 \mathrm{a}$ & $196 b$ & $197 \mathrm{a}$ & $200 \mathrm{a}$ & $200 b$ & $200 c$ & \\
\hline 1 & Grunt/upsweep & 0.15 & 0.02 & 0.33 & 0.00 & 0.15 & 0.06 & 0.05 & 0.14 & 0.00 & 0.12 & 0.00 & 0.06 & 0.40 & 0.00 & 0.05 & 152 \\
\hline 2 & Short grunt/upsweep & 0.20 & 0.06 & 0.00 & 0.00 & 0.21 & 0.15 & 0.31 & 0.24 & 0.39 & 0.17 & 0.00 & 0.18 & 0.60 & 0.67 & 0.32 & 276 \\
\hline 3 & Moans and squeaks & 0.05 & 0.09 & 0.00 & 0.00 & 0.02 & 0.01 & 0.06 & 0.00 & 0.17 & 0.06 & 0.00 & 0.00 & 0.00 & 0.00 & 0.46 & 101 \\
\hline 4 & Upsweep gurgle & 0.02 & 0.65 & 0.33 & 0.00 & 0.04 & 0.44 & 0.00 & 0.18 & 0.11 & 0.02 & 0.00 & 0.32 & 0.00 & 0.33 & 0.05 & 214 \\
\hline 5 & Grunts and wops & 0.31 & 0.12 & 0.00 & 0.00 & 0.13 & 0.00 & 0.14 & 0.02 & 0.06 & 0.09 & 0.00 & 0.12 & 0.00 & 0.00 & 0.02 & 146 \\
\hline 6 & Wops & 0.21 & 0.01 & 0.33 & 1.00 & 0.40 & 0.04 & 0.26 & 0.20 & 0.00 & 0.33 & 0.00 & 0.18 & 0.00 & 0.00 & 0.10 & 371 \\
\hline 7 & Low grunts & 0.01 & 0.01 & 0.00 & 0.00 & 0.02 & 0.26 & 0.02 & 0.16 & 0.22 & 0.06 & 0.00 & 0.03 & 0.00 & 0.00 & 0.00 & 111 \\
\hline 8 & Wops and upsweep grunts & 0.05 & 0.05 & 0.00 & 0.00 & 0.04 & 0.04 & 0.15 & 0.06 & 0.06 & 0.15 & 0.00 & 0.12 & 0.00 & 0.00 & 0.00 & 171 \\
\hline All & Total number of sounds & 86 & 147 & 3 & 1 & 48 & 163 & 93 & 50 & 18 & 845 & 0 & 34 & 10 & 3 & 41 & 1542 \\
\hline
\end{tabular}


this sound type occurs in all three of the major behavioral contexts of humpbacks (feeding, breeding, and migration) and in three different populations (North Pacific, North Atlantic, and East Australian) indicates that it may be an important sound with a flexible context or with multiple uses during different activities. Investigation of the behavioral context of wops on the feeding grounds will provide an interesting comparison to their speculated communicative function on the migration route (Dunlop et al., 2008), and their use as a unit in some songs on the breeding grounds (D. Cholewiak, personal communication).

Grunts have been mentioned in Thompson's 1986 research in the Alaskan feeding grounds, though they may be acoustically different from those reported here. In fact, the grunts described in Dunlop et al. (2007) occur at a faster pace and are lower in frequency than the grunts in this dataset. The grunts here appear to be some combination of Dunlop's "yelps" and "croaks," which were both relatively uncommon sound types on the migration route. Perhaps the grunt sound type reported here is a sound more specific to foraging activities. Further comparisons with humpback sound production on the breeding grounds and in different feeding ground locations will elucidate this.

It is worth noting that comparisons between whale sounds produced in different parts of the world, and recorded by different research groups, can be challenging. It is difficult to come to a consensus when naming and categorizing whale sounds based only on published spectral/waveform images and numbers describing acoustic parameters. We believe the sounds we have described here are similar enough to be likened to some other published humpback non-song sounds. Conversely, one sound, the feeding cry used in southeast Alaska during cooperative foraging, has been described in the literature (D'Vincent et al., 1985; Cerchio and Dalheim, 2001) and is distinctive enough that we can clearly say we did not record any in our North Atlantic datasets. Unfortunately, in most cases, sounds blur together in their parameters and are difficult to typify. Now that journals are capable of accepting multimedia additions to submissions, we encourage research groups to submit representative acoustic files along with manuscripts, so that we can work toward a more cohesive and publicly accessible catalog that describes the repertoire of various marine mammal species.

Nomenclature aside, we hope that these sounds will complement the catalog of Dunlop et al. (2007) and will be useful when scanning passive acoustic monitoring datasets and using automatic detection algorithms to identify humpback whale presence. Sound exemplars recorded using a variety of methodologies should help predict how a sound might look when detected on autonomous hydrophones at varying distances from the source. It will also be important to investigate overall call rates and diel trends in the production of these sounds to help streamline detection and identification of particular sound types.

\section{ACKNOWLEDGMENTS}

Research was conducted under National Marine Fisheries Service Permit No. 981-1707-00 and in accordance with animal care and use guidelines in the United States. We thank Eva-Marie Nosal and Danielle Cholewiak for helpful comments on an earlier version of the manuscript and also numerous field volunteers and colleagues for assistance in data collection. This paper was funded by the National Oceanic and Atmospheric Administration (NOAA)'s National Marine Sanctuaries Program. It was also sponsored in part by the University of Hawaii Sea Grant College Program, School of Ocean and Earth Science and Technology, under Institutional Grant No. NA05OAR4171048 from the NOAA Office of Sea Grant, Department of Commerce, and is publication no. UNIHI-SEAGRANT-JC-07-32. This is also Hawaiì Institute of Marine Biology contribution No. 1400.

${ }^{1}$ See supplemental material at http://dx.doi.org/10.1121/1.3504708 Document No. E-JASMAN-128-038012 for example audio clips of the sounds highlighted in this paper. For more information see http://www.aip.org/pubservs/epaps.html.

Au, W. W. L., Frankel, A., Helweg, D. A., and Cato, D. H. (2001). "Against the humpback whale sonar hypothesis," IEEE J. Ocean. Eng. 26, 295-300.

Au, W. W. L., Mobley, J., Burgess, W. C., Lammers, M. O., and Nachtigall, P. E. (2000). "Seasonal and diurnal trends of chorusing humpback whales wintering in waters off western Maui," Marine Mammal Sci. 16, 530-544.

Au, W. W. L., Pack, A. A., Lammers, M. O., Herman, L. M., Deakos, M. H., and Andrews, K. (2006). "Acoustic properties of humpback whale songs," J. Acoust. Soc. Am. 120, 1103-1110.

Aguilar-Soto, N., Johnson, M., Madset, P. T., Tyack, P. L., Bocconcelli, A., and Borsani, J. F. (2006). "Does intense ship noise disrupt foraging in deep-diving Cuvier's beaked whales (Ziphius cavirostris)?," Marine Mammal Sci. 22, 690-699.

Cerchio, S., and Dahlheim, M. (2001). "Variation in feeding vocalizations of humpback whales Megaptera novaeangliae from southeast Alaska," Bioacoustics 11, 277-295.

Chu, K. C. (1988). "Dive times and ventilation patterns of singing humpback whales (Megaptera novaeangliae)," Can. J. Zool. (Revue Canadienne De Zoologie) 66, 1322-1327.

Chu, K., and Harcourt, P. (1986). "Behavioral correlations with aberrant patterns in humpback whale songs," Behav. Ecol. Sociobiol. 19, 309-312.

Darling, J. D., Jones, M. E., and Nicklin, C. P. (2006). "Humpback whale songs: Do they organize males during the breeding season?," Behaviour 143, 1051-1101.

Deecke, V. B., and Janik, V. M. (2006). "Automated categorization of bioacoustic signals: Avoiding perceptual pitfalls,” J. Acoust. Soc. Am. 119, 645-653.

Dunlop, R. A., Cato, D. H., and Noad, M. J. (2008). "Non-song acoustic communication in migrating humpback whales (Megaptera novaeangliae)," Marine Mammal Sci. 24, 613-629.

Dunlop, R. A., Noad, M. J., Cato, D. H., and Stokes, D. (2007). “The social vocalization repertoire of east Australian migrating humpback whales (Megaptera novaeangliae)," J. Acoust. Soc. Am. 122, 2893-2905.

D’Vincent, C. G., Nilson, R. M., and Hanna, R. E. (1985). "Vocalization and coordinated feeding behavior of the humpback whale in southeastern Alaska," Scientific Reports of the Whales Research Institute, Tokyo 36.

Frankel, A. S., Clark, C. W., Herman, L. M., and Gabriele, C. M. (1995). "Spatialdistribution, habitat utilization, and social interactions of humpback whales, Megaptera novaeangliae, off Hawaii, determined using acoustic and visual techniques," Can. J. Zool. (Revue Canadienne De Zoologie) 73, 1134-1146.

Frazer, L. N., and Mercado, E. (2000). "A sonar model for humpback whale song,” IEEE J. Ocean. Eng. 25, 160-182.

Johnson, M. P., and Tyack, P. L. (2003). "A digital acoustic recording tag for measuring the response of wild marine mammals to sound," IEEE J. Ocean. Eng. 28, 3-12.

Lippsett, L. (2009). "Buoys help avert whale-ship collisions," Oceanus 47, 1-9. Mellinger, D. K., Stafford, K. M., Moore, S. E., Dziak, R. P., and Matsumoto, H. (2007). "An overview of fixed passive acoustic observation methods for cetaceans," Oceanography 20, 36-45.

Miller, P. J. O., Biassoni, N., Samuels, A., and Tyack, P. L. (2000). "Whale songs lengthen in response to sonar," Nature (London) 405, 903. 
Mills, H. G., and Figueroa, H. K. (2005). "Extensible bioacoustical analysis software: Two examples (Abstract)," J. Acoust. Soc. Am. 117, 2525.

Noad, M. J., Cato, D. H., Bryden, M. M., Jenner, M. N., and Jenner, K. C. S. (2000). "Cultural revolution in whale songs," Nature (London) 408, 537.

Parks, S. E., and Tyack, P. L. (2005). "Sound production by North Atlantic right whales (Eubalaena glacialis) in surface active groups," J. Acoust. Soc. Am. 117, 3297-3306.

Payne, R. S., and McVay, S. (1971). "Songs of humpback whales," Science 173, 585-597.

Rankin, S., and Barlow, J. (2005). "Source of the North Pacific 'boing' sound attributed to minke whales," J. Acoust. Soc. Am. 118, 3346-3351.

Riesch, R., Ford, J. K. B., and Thomsen, F. (2006). "Stability and group specificity of stereotyped whistles in resident killer whales, Orcinus orca, off British Columbia," Anim. Behav. 71, 79-91.

Silber, G. K. (1986). "The relationship of social vocalizations to surface behavior and aggression in the Hawaiian humpback whale (Megaptera novaeangliae)," Can. J. Zool. (Revue Canadienne De Zoologie) 64, 2075-2080.

Smith, J. N., Goldizen, A. W., Dunlop, R. A., and Noad, M. J. (2008). "Songs of male humpback whales, Megaptera novaeangliae, are involved in intersexual interactions," Anim. Behav. 76, 467-477.

Spaulding, E., Robbins, M., Calupca, T., Clark, C. W., Tremblay, C. J., Waack, A., Warde, A. M., Kemp, J., and Newhall, K. (2010). "An autono- mous, near-real-time buoy system for automatic detection of North Atlantic right whale calls," Proc. Meet. Acoust. 6, 1-22.

Stafford, K. M., Nieukirk, S., and Fox, C. G. (1999). "Low-frequency whale sounds recorded on hydrophones moored in the eastern tropical Pacific," J. Acoust. Soc. Am. 106, 3687-3698.

Thompson, P. O., Cummings, W. C., and Ha, S. J. (1986). "Sounds, source levels, and associated behavior of humpback whales, Southeast Alaska," J. Acoust. Soc. Am. 80, 735-740.

Tyack, P. (1983). "Differential response of humpback whales, Megaptera novaeangliae, to playback of song or social sounds," Behav. Ecol. Sociobiol. 13, 49-55.

Van Parijs, S. M., Clark, C. W., Sousa-Lima, R. S., Parks, S. E., Rankin, S., Risch, D., and Van Opzeeland, I. C. (2009). "Management and research applications of real-time and archival passive acoustic sensors over varying temporal and spatial scales," Mar. Ecol.: Prog. Ser. 395, 21-36.

Winn, H. E., Thompson, T. J., Cummings, W. C., Hain, J., Hudnall, J., Hays, H., and Steiner, W. W. (1981). "Song of the humpback whalePopulation comparisons," Behav. Ecol. Sociobiol. 8, 41-46.

Zoidis, A. M., Smultea, M. A., Frankel, A. S., Hopkins, J. L., Day, A., McFarland, A. S., Whitt, A. D., and Fertl, D. (2008). "Vocalizations produced by humpback whale (Megaptera novaeangliae) calves recorded in Hawaii,” J. Acoust. Soc. Am. 123, 1737-1746. 